\title{
o terrorismo de estado (TDE) no Rio Grande do Sul: perseguição, prisão e tortura de militantes da vanguarda Popular Revolucionária (VPR)
}

\section{Cristiane Medianeira Ávila Dias*}

As atividades da Vanguarda Popular Revolucionária (VPR) no Rio Grande do Sul tiveram início em 1969 e se concentraram de forma prioritária na região metropolitana de Porto Alegre. A ação de maior vulto da VPR foi a tentativa de sequestro do cônsul americano Curtis Carly Cutter, realizada em abril de 1970, episódio que acirrou a repressão desferida pelos órgãos de segurança contra a organização, pois logo grande parte de seus militantes foram presos e encaminhados a Delegacia de Ordem Política e Social (DOPS), onde foram submetidos a sessões de tortura física e psicológica. Os métodos de violência sistemática, como a tortura, utilizados pelo aparato estatal para combater os grupos de oposição, caracterizaram a aplicação do Terrorismo de Estado (TDE) pelo governo militar brasileiro no espaço estadual.

Palavras-chave: Vanguarda Popular Revolucionária (VPR) - Terrorismo de Estado (TDE) - Rio Grande do Sul

\section{o surgimento da Vanguarda Popular Revolucionária \\ (VPR)} m agosto de 1961, Jânio Quadros renuncia o cargo de presidente e partes das Forças Armadas Brasileiras articularam um plano para impedir a posse do vice-presidente João Goulart, naquele momento em viagem pela China.

\footnotetext{
* Mestre em História - Universidade de Passo Fundo (UPF). cristiane-historia@hotmail.com
} 
The activities of the Popular Revolutionary Vanguard (VPR) in Rio Grande do Sul began in 1969 and focused essentially on the metropolitan region of Porto Alegre. The largest action of the VPR was the attempted kidnapping of the American Consul Curtis Carly Cutter, held in April 1970, an episode that incited the repression launched by security agencies against the organization, as soon most of its members were arrested and sent to the Delegacia de Ordem Política e
Social (DOPS), where they were subjected to physical and psychological torture sessions. The methods of systematic violence, such as torture, used by the state apparatus to fight the opposition groups characterized the application of State Terrorism by the military government in the state.

Keywords: Popular Revolutionary Vanguard (VPR) - State Terrorism - Rio Grande do Sul

Diante disso, Leonel Brizola, então governador do Rio Grande do Sul, iniciou um movimento em defesa da posse, conhecida como a "Campanha da Legalidade". Essa campanha garantiu a chegada de João Goulart à presidência, mas não impediu que ele tivesse seus poderes reduzidos através de uma manobra política que instaurou o sistema parlamentarista no país. Esse fato desagradou principalmente o grupo formado pelos militares nacionalistas. Apesar do desfecho negativo, a campanha beneficiou esses militares que saíram dela fortalecidos e com um nível mais elevado de conscientização política. A experiência alcançou visibilidade nacional na medida em que seus integrantes eram transferidos para servirem em outras regiões do país: "cada sargento se transformou numa célula de propaganda política do movimento nacionalista". ${ }^{1}$

A efervescência política que vivia o Brasil no início da década de 1960 também afetou o Partido Comunista Brasileiro (PCB), que perdeu sua hegemonia sobre a esquerda brasileira, devido ao fato de vários militantes, descontentes com a falta de mobilidade da sua direção nacional, se desligaram do partido para formar outros grupos políticos, entre os quais, a Organização Revolucionária Marxista-Política Operária (ORM-POLOP), criada em fevereiro de 1961. Na interpretação da POLOP, o Brasil já era um país plenamente capitalista e a revolução não deveria ter duas fases, como previa o PCB, e sim assumir de forma imediata um caráter socialista, posição

${ }^{1}$ COSTA, José Caldas. Caparaó, a primeira guerrilha contra a ditadura militar. São Paulo: Boitempo, 2007, p. 64. 
que impediu a organização de interagir com o partido e os demais grupos vinculados a João Goulart e a deixou isolada do cenário político nacional. A situação mudou apenas no momento em que seus militantes se aproximaram de Leonel Brizola e dos grupos nacionalistas por ele liderados que, no final de 1963, mostravam-se descontentes com os rumos tomados pelo governo Goulart e, preparavam-se para um possível golpe militar através de formação do chamado "Grupos dos Onze", organização que contou com a adesão da POLOP. ${ }^{2}$

As atividades da POLOP e das demais organizações de esquerda foram interrompidas pelo golpe civil-militar de 1964 que derrubou o presidente João Goulart e inaugurou uma fase de repressão política voltada principalmente contra integrantes de partidos e sindicatos que apoiavam o governo deposto, como os integrantes da Frente de Mobilização Popular (FMP). A chamada "Operação Limpeza" foi decretada pelo Ato Institucional $n^{\circ} 1, A I-1$, que determinou a cassação dos direitos políticos de vários cidadãos acusados de integrarem movimentos políticos "subversivos", a instauração de inquéritos policiais militares (IPMs) e processos administrativos para afastar de suas atividades os funcionários públicos considerados "inimigos" do regime. Os sindicatos sofreram intervenção governamental, as Ligas Camponesas foram dissolvidas e a sede da União Nacional dos Estudantes (UNE), principal símbolo do movimento estudantil em âmbito nacional, foi incendiada. O número de pessoas detidas foi tão elevado que muitas tiveram que ser enviadas para "navios-presídios". 3

O Rio Grande do Sul, devido à vinculação de políticos locais com o governo João Goulart e sua própria tradição trabalhista, foi um dos estados mais atingidos pela Operação Limpeza. Assim, logo após o golpe, o governo militar iniciou uma campanha de perseguição contra os políticos vinculados ao Partido Trabalhista Brasileiro (PTB), ao mesmo tempo em

\footnotetext{
${ }^{2}$ MATTOS, Marcelo Badaró. Em busca da revolução socialista: a trajetória da POLOP (1961-1967). In: RIDENTI, Marcelo; AARÃO REIS, Daniel (orgs). História do marxismo no Brasil. Partidos e organizações dos anos 20 aos 60. Vol.5. Campinas, SP: Editora da Unicamp, 2002, p. 194.
}

${ }^{3}$ GORENDER, Jacob. Combate nas trevas. 5 ed. São Paulo: Ática, 1998, p. 77. 
que decretou o afastamento de funcionários públicos estaduais e transferiu para a reserva militarem envolvidos com o movimento nacionalista. A saída encontrada por vários gaúchos perseguidos foi partir para o exílio no Uruguai, país escolhido pela proximidade geográfica e por ser uma das mais sólidas democracias da América Latina. Logo, o país vizinho tornou-se residência de João Goulart, Leonel Brizola e de vários outros políticos, que começaram a organizar a partir do exílio movimentos de oposição a ditadura civil-militar brasileira, utilizando para isso o trabalho dos chamados "pombos-correios", indivíduos que percorriam regularmente o trajeto Porto Alegre-Montevidéu na tentativa de articular a resistência. ${ }^{4}$

Nessa fase, a POLOP tentava reunir cabos, marinheiros, soldados e sargentos para dar início a luta armada, organizando no Rio de Janeiro a chamada "Guerrilha de Copacabana", que foi rapidamente descoberta e desmantelada pelos órgãos de segurança. Os militares de baixa patente que conseguiram fugir da repressão e se exilaram no Uruguai fundaram com Leonel Brizola fundaram o Movimento Nacional Revolucionário (MNR). As atividades do MNR consistiram, por exemplo, na tentativa de implantar um foco guerrilheiro numa região localizada entre as fronteira dos estados do Rio de Janeiro, Espírito Santo e Minas Gerais, a "Guerrilha do Caparaó", mas o movimento também foi descoberto pelos órgãos de segurança e aniquilado em 1967, com a prisão de todos os militantes em atividade na área. ${ }^{5}$

As derrotas sofridas pelo MNR e a POLOP na fase pós-golpe fizeram com que vários militantes deixassem as respectivas organizações para fundar oficialmente em dezembro de 1968, a Vanguarda Popular Revolucionária (VPR). Já na fase da fundação, a VPR optou por seguir o referencial ideológico defendido por Ladislau Dowbor, o "Jamil”, que previa a partida imediata da organização para a luta armada, sendo que suas primeiras ações consistiram no furto de onze fuzis do Hospital Militar do Cambuci e na explosão de uma bomba no alojamento de oficiais do II Exército, locali-

\footnotetext{
${ }^{4}$ PADRÓS, Enrique Serra (Org.). A ditadura de Segurança Nacional no Rio Grande do Sul: 1964-1985. História e Memória. Vol.2. Porto Alegre: Corag, 2009, p. 46.
}

${ }^{5}$ MATTOS, Marcelo Badaró. Op. cit., p. 185-208. 
zado no Bairro do Ibirapuera, que ocasionou a morte de um soldado que trabalhava de sentinela no local. A organização também foi responsável pelo atentado que resultou na morte de Charles Chandler ${ }^{6}$, um agente da Central Americana de Inteligência (CIA), que fazia curso no Brasil e pleno plano ousado no qual um carregamento de armas foi retirado do quartel onde servia o Capitão do Exército Carlos Lamarca, que deixou as Forças Armadas para militar na VPR em 19697. No Rio Grande do Sul, os órgãos de segurança divulgaram as fotografias do "Capitão Lamarca", "Sargento Darcy", "Cabo Mariani" e do "Soldado Zanirato", como os responsáveis pelo furto das armas em São Paulo. ${ }^{8}$

A opção que a VPR e outras organizações de esquerda fizeram pela luta armada, não apenas no Brasil, como em toda a América Latina, refletiam o próprio contexto político do período, marcado em nível mundial pela disputa não declarada entre o Estados Unidos e a União Soviética, conflito que recebeu a denominação de Guerra Fria e, em nível regional, pela eclosão da Revolução Cubana no ano de 1959. O movimento cubano abriu novas perspectivas para a esquerda latino-americana, ao apresentar um modelo de socialismo diferenciado daquele proposto pela União Soviética e a China, mais adaptado aos problemas econômicos políticos e sociais que afetavam a região. Desse modo, grupos formados principalmente por dirigentes sindicais, trabalhadores do campo e da cidade, padres, intelectuais, artistas e militantes do movimento estudantil, assumiram suas preocupações com a desigualdade social e se mobilizaram para implantar projetos reformistas ou revolucionários que pudessem modificar a situação de miséria em que

\footnotetext{
${ }^{6} \mathrm{O}$ capitão norte-americano Charles Rodney Chandler era veterano da guerra do Vietnã. Bolsista de uma fundação dos Estados Unidos frequentava o curso de Sociologia e Política e, supostamente aprendia o idioma português para fins de ensino na Academia Militar de West Point. (...) Ao cair fulminado, Chandler trazia uma obra de doutrinação anticomunista. GORENDER, Jacob. Op. cit., p. 144.

${ }^{7}$ GORENDER, Jacob. Idem.

${ }^{8}$ Arquivo Histórico do Rio Grande do Sul /Fundo: Secretaria da Segurança Pública/ Subfundo: Polícia Civil/Departamento de Polícia do Interior/ $20^{\mathrm{a}}$ Região Policial/ Delegacia Regional de Cachoeira do Sul/ SOPS/ SOPS/CS 1.2.1311.17.5, "Circular para as delegacias regionais", Porto Alegre, 25 de fevereiro de 1969.
} 
viviam a maior parte da população local: “a Revolução Cubana gerou, sem dúvida, uma expectativa de futuro diferente daquela das gerações anteriores, ou seja, um futuro possível de ser construído com voluntarismo e ação política, com participação, mobilização e organização". 9

No caso do Brasil, as ações armadas efetuadas pela VPR em São Paulo, entre as quais a fuga do ex-capitão Carlos Lamarca de sua unidade com um carregamento de armas, chamaram a atenção dos órgãos de segurança e eles passaram a desferir uma intensa repressão contra o grupo, que resultou na prisão de vários militantes e afetou a estrutura da organização ${ }^{10}$. Assim, na busca de reorganizar sua força política, a VPR decidiu se unir ao Comando de Libertação Nacional (COLINA), organização formada por dissidentes da POLOP que atuava principalmente em Minas Gerais, para fundar a Vanguarda Armada Revolucionária Palmares, a VAR-Palmares (VAR-P), em junho de 1969. A união entre as duas organizações, entretanto, durou pouco tempo, pois em setembro os seus militantes entraram em divergências internas e parte deles resolveu manter a VAR-Palmares enquanto outro grupo decidiu resgatou a antiga sigla da VPR. A "nova" VPR se uniu aos militantes dissidentes no Rio de Janeiro e Rio Grande do Sul e decidiu partir de forma imediata para a luta armada, abandonando o trabalho político e a formação de bases. ${ }^{11}$

No Rio Grande do Sul, conforme informações de João Carlos Bona Garcia, o braço armado da VPR foi montado em 1969 no "aparelho", um apartamento utilizado pela organização para guardar material e realizar reuniões, localizado no Bairro Petrópolis, em Porto Alegre. A primeira atividade armada da qual o ex-militante fez parte foi o assalto ao carro que

\footnotetext{
${ }^{9}$ PADRÓS, Enrique Serra. Segurança Nacional. In: PADRÓS, Enrique Serra (Org.). $O p$. cit. , p.51.

${ }^{10}$ Arquivo Histórico do Rio Grande do Sul /Fundo: Secretaria da Segurança Pública/ Subfundo: Polícia Civil/Departamento de Polícia do Interior/ 20a Região Policial/ Delegacia Regional de Cachoeira do Sul/ SOPS/ SOPS/CS 1.2.1323.17.5 "Relação de integrantes da vanguarda Popular Revolucionária que se encontram foragidos", Porto Alegre, 12 de junho de 1969.
}

${ }^{11}$ ARNS, Paulo Evaristo. Brasil: Nunca Mais. Petrópolis, Rio de Janeiro: Vozes, 1985. 
arrecadava o dinheiro da Ultragás na região de Canoas, realizada em março de 1970, mas a ação de maior vulto, no entanto, ocorreu no mês de abril, quando a VPR planejou o sequestro do embaixador norte-americano Curtis Carly Cutter, que acabou não dando certo, porque o cônsul, veterano da guerra da Coréia, jogou sua caminhonete contra o fusca dirigido pelos militantes, frustrando a ação. O episódio foi apontado por Bona Garcia como a causa principal do extermínio das organizações de luta armada no estado, porque após o episódio foram enviados do Rio de Janeiro dois oficiais do Exército especializados na aplicação de tortura chamados "Malhães" e "Cabral", para treinar os agentes locais. ${ }^{12}$

\section{O terrorismo de Estado (TDE) no Brasil}

O surgimento de organizações como a VPR, COLINA e a VAR-P, assim como o súbito aumento da luta armada colocou em xeque a preparação do aparato estatal para enfrentar esses grupos. Desse modo, a ineficiência do Departamento Estadual de Ordem Política e Social (DEOPS) de São Paulo e a falta de organização no interior das Forças Armadas, fez surgir à ideia de fundar uma entidade capaz de mobilizar homens e recursos na chamada "luta contrarrevolucionária" e, como o estado concentrava a grande parte das ações da guerrilha, foi escolhido para sediar a "Operação Bandeirante" (OBAN). O projeto piloto, fundado em junho de 1969, centralizou de forma extralegal numa só instituição, todas as ações de militares e policiais contra as organização de esquerda. A operação alcançou tanto êxito que o Presidente Emílio Médici decretou em 1970, a integração da OBAN ao organograma legal sobre a denominação Destacamento de Operações de Informações/Centro de Operações de Defesa Interna (DOI/CODI) do II Exército. ${ }^{13}$

O aperfeiçoamento do aparato repressivo estatal tornou-se possível, no caso brasileiro, após a decretação do Ato-Institucional nº5, AI-5, em

\footnotetext{
${ }^{12}$ GARCIA, João Carlos Bona; POSENATO, Júlio. Verás que um filho teu não foge a luta. Porto Alegre: Posenato Arte e Cultura, 1989, p. 41.
}

${ }^{13}$ GORENDER, Jacob, Op. cit., p. 171. 
dezembro de 1968, pois permitiu que os órgãos de segurança agissem sem nenhuma restrição contra indivíduos supostamente envolvidos em atividades políticas "subversivas", ou seja, qualquer pessoa podia ser presa para "averiguação" de informações, sem que houvesse uma acusação formal ou um mandado judicial expedido contra ela. A justificativa utilizada pelo governo militar para implantar as medidas arbitrárias e a necessidade de mais "segurança interna" eram as ações da guerrilha urbana. A "estratégia de controle pelo terror" se institucionalizou de tal forma que atingiu não apenas as organizações de esquerda que haviam optado pela luta armada, como setores de oposição que haviam optado por outras estratégias de luta e grande parte da população brasileira não envolvida em atividades políticas. Assim, qualquer cidadão podia ser atingido pela repressão estatal, fazendo com que o AI-5 marcasse o início de um período da história caracterizado pelo "silêncio, o medo, a confusão e o desânimo". ${ }^{14}$

A decretação do AI-5, na avaliação de Padrós, foi o dispositivo que permitiu a Ditadura de Segurança Nacional Brasileira instaurar o Terrorismo de Estado (TDE), na medida em que a violência passou a fazer a mediação entre o Estado e a sociedade, em nome da pretensa "segurança nacional". Nesse sentido, durante o período em que vigorou a ditadura no Brasil, o Estado, ao invés de garantir a segurança da população, utilizou o aparato institucional para coibir as ações dos grupos de oposição e, baseando suas práticas na Doutrina de Segurança Nacional (DSN), não teve preocupação em extrapolar os limites coercitivos constitucionais, fato que desencadeou as práticas e ações que acabaram configurando um sistema TDE. ${ }^{15}$

Para Ballesteros, as condições de enfrentamento na América Latina surgiram a partir da dependência econômica imposta pelas metrópoles im-

\footnotetext{
${ }^{14}$ ALVES, Maria Helena Moreira. Estado e oposição no Brasil (1964-1984). Petrópolis: Vozes, 1989, p.136.

${ }^{15}$ PADRÓS, Enrique Serra. Como el Uruguay no hay...:Terror de Estado e Segurança Nacional. Uruguai (1968-1985): do Pachecato à ditadura civil-militar. Porto Alegre: UFRGS, 2005. Tese (Doutorado História) - Programa de Pós-Graduação em História, Instituto de Filosofia e Ciências Humanas, Universidade Federal do Rio Grande do Sul, Porto Alegre, 2005. $2 \mathrm{t}$.
} 
perialistas aos países da região, que beneficiavam os setores dominantes, mas não resolviam os problemas da porção miserável e marginalizada da sociedade. Esse modelo de sociedade excludente era fonte de tensões e conflitos sociais permanentes, que eclodiram com mais força na década de 1960, impulsionadas principalmente pela Revolução Cubana. Nesse período, as estratégias adotadas pelos setores dominantes não foram suficientes para impedir a ascensão dos movimentos sociais e a saída encontrada por eles, na tentativa de manterem seus privilégios não foi o diálogo nem a busca de consenso, mas recorrer a um novo tipo de repressão, conhecida como mais eficiente no combate aos conflitos e a "subversão". A chamada "guerra contra revolucionária", baseada nas premissas da DSN, utilizaria novos métodos e técnicas para sistematizar e tornar mais eficiente o aparato repressivo empregado na luta contra todo e qualquer movimento de oposição. ${ }^{16}$

Na interpretação da doutrina, o cidadão só se realizava enquanto indivíduo ao tomar consciência do seu pertencimento à nação, e que esta comunidade "coesa" era a única capaz de atender e satisfazer as duas demandas. A pessoa que discordava publicamente dessa concepção baseada nos valores "ocidentais e cristãos", era acusada de se identificar com "ideologias estranhas" e considerada um "inimigo perigoso" a ser combatido pelo Estado. O Brasil, como o primeiro país a instaurar uma ditadura baseada nas premissas da DSN, criou um aparato repressivo estatal que serviu de modelo para os demais governos militares que se instauram posteriormente na região, entre os quais o Uruguai (1973), Chile (1973) e a Argentina (1976) que, apesar das especificidades apresentadas por cada caso, apresentaram uma base comum formada pelas seguintes características: "a existência de um anticomunismo militante, a identificação de um inimigo interno, a implantação de uma guerra de contra-insurgência, o protagonismo político das Forças Armadas e o primado das fronteiras ideológicas". ${ }^{17}$

\footnotetext{
${ }^{16}$ BALLESTEROS, Elías Padilha. La memoria y el olvido. Detenidos Desaparecidos en Chile. Santiago: Orígenes Ediciones, 1995, p.31.
}

${ }^{17}$ PADRÓS, Enrique Serra. Op. cit., p. 59. 
Para as Forças Armadas Brasileiras, a América Latina vivenciava naquele momento uma guerra revolucionária e o papel dos militares nesse conflito era combater o comunismo e as ações "subversivas" e "maléficas" empreendidas por indivíduos considerados "traidores" e "inimigos da pátria". Na interpretação dos analistas militares, as relações entre os blocos comunista e capitalista estavam calmas, o que inviabilizava a ocorrência de uma terceira Guerra Mundial, mas não impedia que eclodisse uma guerra de "outro tipo", estruturada de forma clandestina pela subversão dentro do próprio território nacional; a chamada guerra revolucionária, que iria abranger toda a região e seria liderada por Fidel Castro com o apoio da União Soviética, numa forma de combate diferenciada, para o qual eles não estariam devidamente preparados:
A América Latina já está profundamente envolvida nesta guerra dife- rente, onde a ação dissimulada e subreptícia são a principal e na qual a luta armada, em escala considerável, terá lugar apenas na etapa final. É a guerra do comunismo contra toda a AMÉRICA livre, declarada em Havana, em Jan 66. Suas ações desenvolvem-se em escala crescente, sem que nenhum dos países atingidos tenha, até o presente, mobilizado recursos eficazes para obstá-las. ${ }^{18}$

A Doutrina de Segurança Nacional (DSN) foi uma série de pressupostos teóricos criados por estrategistas norte-americanos a partir das experiências vivenciadas no Vietnã, na Indochina e na Argélia, e na suposta necessidade de responder a nova técnica de guerra empregada pelos subversivos desses países. Os americanos foram influenciados por franceses, entre os quais o coronel Robert Trinquier, para o qual a guerra revolucionária era apenas uma questão de controle da população através do terror, pois sua aplicação deixaria o grupo clandestino isolado politicamente e abriria espaço para ele fosse aniquilado pelos militares. As táticas utilizadas eram as mais diversas e tinham por finalidade liquidar não apenas os subversivos, mas todos aqueles que pudessem se tornar possíveis colaboradores da

\footnotetext{
${ }^{18}$ Arquivo Histórico do Rio Grande do Sul /Fundo: Secretaria da Segurança Pública/ Subfundo: Polícia Civil/Departamento de Polícia do Interior/ 15ª Região Policial/ Delegacia Regional de Lagoa Vermelha/ SOPS/ SOPS/LV_1._43.1.1, "Documento A", Porto Alegre, 09 de outubro de 1967.
} 
revolução, como militantes de partidos de esquerda que simpatizavam com a causa, entre outros grupos. Para detectar a presença do inimigo, o militar aconselhava a utilização da tortura, que era a principal fonte de informação, já que durante a aplicação do método o revolucionário perderia sua moral e forneceria todos os dados que os agentes precisavam para agir contra a organização clandestina da qual ele fazia parte. ${ }^{19}$

Na interpretação de Viñar, as Ditaduras de Segurança Nacional que se instalaram na América Latina durante as décadas de 1960 e 1970 se diferenciavam dos regimes implantados em épocas anteriores porque utilizaram de forma racional e sistemática a violência para combater a oposição política e os indivíduos considerados inimigos do Estado. No sistema implantado pelas Forças Armadas, a "tortura representou o papel de peça mestra" e, demonstrou o nível planificado que a repressão política e social, baseada nas premissas da DSN, alcançou em toda a região no período. A tortura foi empregada pelos governos militares dentro de uma determinada "lógica de poder político" e não foi apenas, como defendem alguns pesquisadores, uma "manifestação arcaica da organização social”. A definição de tortura, nesse caso, pode ser aquela descrita por Michel de Certeau:

A tortura é uma prática administrativa de rotina que cresce com a centralização tecnocrática. Longe de estar em posição de exterioridade em relação à civilização contemporânea, é um sintoma e um efeito inerentes ao poder, quando este perde a sua capacidade de organização própria, de racionalidade administrativa, para escrever a história no martírio dos corpos. Os torturados pagam pelo funcionamento social do qual tiramos proveito. Eles seriam o seu reverso e sua condição. ${ }^{20}$

Para Padrós, a tortura já era conhecida e utilizada na região e a novidade do período foi os torturadores terem utilizado a "criatividade" e os "avanços tecnológicos" para aperfeiçoarem os métodos de produção da dor. O mais importante porém, é reconhecer o uso massivo e significativamen-

${ }^{19}$ COMBLIN, Joseph. A ideologia da Segurança Nacional. O Poder Militar na América Latina. 3. ed. Rio de Janeiro:Civilização Brasileira, 1980, p. 46.

${ }^{20}$ Michel de Certeau apud VIÑAR, Maren e Marcelo. Exílio e tortura. São Paulo: Escuta, 1992, p. 135. 
te indiscriminado da tortura e também a existência da complexa rede de transmissão de novas técnicas e de formação de novos especialistas através de uma correia de transmissão que ultrapassou fronteiras e recebeu o apoio de agências norte-americanas e de missões francesas; umas e outras possibilitaram incorporar as novidades da contra insurgência experimentada na Argélia e no Vietnã: "o uso massivo da tortura, os esquadrões da morte, os desaparecimentos e a internacionalização do sistema repressivo, mesmo guardando especificidades em cada contexto nacional, foram modalidades mais específicas do TDE empregado pelos regimes de SN na região". ${ }^{21}$

Nesse contexto, nos anos de 1966 e 1967, a polícia brasileira carecia de informações sobre os movimentos de oposição, pois a Marinha tinha dossiês completos sobre as atividades "subversivas" no país, mas não compartilhava a informação com os outros serviços de segurança. Na tentativa de resolver o problema, os agentes da repressão começaram a empregar métodos mais severos para obter informações dos presos, ensinados por policiais que haviam utilizado a tortura durante a ditadura de Getúlio Vargas (1937-1945). As técnicas eram brutais e ineficazes, pois o preso era espancado de tal forma que, na maioria das vezes, morria antes de fornecer qualquer tipo de informação. Assim, os policiais, com o auxílio de agentes como Dan Mitrione, enviado pelo governo dos Estados Unidos para treinar a polícia brasileira, começaram a utilizar equipamentos e técnicas mais aprimoradas na aplicação da tortura: "quando oficiais brasileiros dos serviços de informações passaram a utilizar telefones de campanha para administrar choques elétricos, foram agentes norte-americanos que lhes informaram quais os níveis permissíveis para o corpo humano". ${ }^{22}$

De acordo com Vargas, o que torna a tortura uma arma especialmente eficaz e faz com que o método forme o eixo principal de qualquer política terrorista são as suas qualidades. A primeira delas é o fato do método ser clandestino, o que garante a sua invisibilidade, a segunda é os torturadores terem certeza que não serão julgados e punidos pelos seus crimes, a

${ }^{21}$ PADRÓS, Enrique Serra. Op. cit., p. 110.

${ }^{22}$ LANGGUTH, A.J. A face oculta do terror. São Paulo: Círculo do Livro, 1978, p. 134. 
terceira é a capacidade que tem a tortura de espalhar o terror e o medo na população e a última, e não menos importante, é a desmoralização que ela impõe as principais lideranças dos movimentos de oposição. Além disso, a dificuldade que as vítimas têm de denunciar os suplícios sofridos contribui de maneira significativa para perpetuar a impunidade, situação que se torna mais perversa quando a tortura é aplicada por funcionários a serviço do Estado, que supostamente deveria proteger os cidadãos da violência, como foi o caso dos países do Cone Sul em que vigoraram ditaduras de Segurança Nacional nas décadas de 1960 e $1970 .{ }^{23}$

No espaço do Rio Grande do Sul, a repressão atingiu de forma mais intensa os militantes de esquerda entre o final de 1969 e o início de 1970. Os militantes Claúdio Weyne Gutierrez e João Carlos Bona Garcia $^{24}$ apontaram a tentativa de sequestro do cônsul americano Curtis Carly Cutter em Porto Alegre, realizada no início de abril de 1970, como a causa principal da extinção das organizações de esquerda armada no Rio Grande do Sul, pois logo após o episódio, militares encarregados de dirigir os DOI/CODI do Rio de Janeiro e São Paulo enviaram dois de seus melhores agentes, conhecidos por "Malhães" e "Cabral", para treinarem os policiais e militares do estado em técnicas de interrogatório: "o DOPS/ RS se tornou uma filial da OBAN". ${ }^{25}$ Logo após a tentativa de sequestro do cônsul, uma circular enviada as delegacias do interior do estado autorizava os policiais a entrarem nas residências e efetuarem prisões no sentido de desbaratar a rede subversiva que havia planejado a ação em Porto Alegre. ${ }^{26}$

\footnotetext{
${ }^{23}$ VARGAS, Patricio Orellana. La represión em Chile, 1973-1989. Santiago, 1992.

${ }^{24}$ GARCIA, João Carlos Bona; POSENATO, Júlio. Op. cit., p. 41.

${ }^{25}$ GUTIÉRREZ, Cláudio Antônio Weyne. A guerrilha Brancaleone. Porto Alegre: Proletra, 1999.

${ }^{26}$ Arquivo Histórico do Rio Grande do Sul /Fundo: Secretaria da Segurança Pública/ Subfundo: Polícia Civil/Departamento de Polícia do Interior/ $20^{\mathrm{a}}$ Região Policial/ Delegacia Regional de Cachoeira do Sul/ SOPS/ SOPS/CS 1.-.71.1.1, "Radiograma", 08 de abril de 1970 .
} 


\section{O TDE no Rio Grande do Sul: perseguição, prisão e tortura de militantes da VPR}

Ananda Fernandes apontou a queda da Aliança Libertadora Nacional (ALN) e o "esquema de fronteira", ou seja, a fronteira do Rio Grande do Sul era utilizada como rota de fuga para integrantes da luta armada, no segundo semestre de 1969, como o evento que alertou os órgãos de segurança para a necessidade de monitorar o espaço estadual de forma mais rigorosa. O estado tornou-se assim, ao mesmo tempo, um espaço onde se articulava uma relativa resistência a ditadura através de uma conexão entre os exilados brasileiros, a oposição interna e uma área de importância fundamental para a repressão, fazendo com que os agentes se unissem para estruturar uma ação integrada, a chamada "Operação Minuano". ${ }^{27}$

O documento intitulado "síntese de ocorrências suspeitas" corrobora as informações fornecida pela pesquisadora sobre a Operação Minuano, que previa em janeiro a possível execução de atividades "subversivas", como assaltos a bancos, sequestros e atentados contra autoridades locais, no mês de maio, dirigidas por liderança de destaque no movimento subversivo nacional. A tarefa dos órgãos de segurança estaduais era impedir o êxito de tais ações, através da aplicação das seguintes medidas:

a) Controlar em cada área e ao longo das rodovias, mediante severa fiscalização, a população flutuante, fazendo-se a identificação e triagem pelos órgãos de informação, após consultados, no caso de suspeitos; b) Operações do (tipo "varredura") em área da capital e do interior onde haja suspeitos ou aglomerações de marginais, como medida preventiva e dissuasória (ação de presença); c) Difundir para fins de providências de policiamento às áreas mais sensíveis a assaltos que possam se con-

\footnotetext{
${ }^{27}$ FERNANDES, Ananda Simões. Quando o inimigo ultrapassa a fronteira: as conexões repressivas entre a ditadura civil-militar brasileira e o Uruguai (1964-1973). Porto Alegre: UFRGS, 2009. Dissertação (Mestrado História) - Programa de Pós-Graduação em História, Instituto de Filosofia e Ciências Humanas, Universidade Federal do Rio Grande do Sul, Porto Alegre, 2009, p. 98.
} 
cretizar a curto prazo; d) Aumentar, com perfeito entrosamento entre todas as forças, as medidas de segurança às autoridades, em particular, àquelas que nos visitam. ${ }^{28}$

Nessa fase, o monitoramento da VPR estava relacionado principalmente a possível presença e colaboração de Carlos Lamarca nas atividades que a organização desenvolvia em cidades do interior ou na capital do Rio Grande do Sul. ${ }^{29} \mathrm{O}$ relatório produzido no final de janeiro, por exemplo, indicava as providências a serem tomadas para a captura de Lamarca:

Fato-ocorrência de Informe: Foram recebidos de diversas localidades e fontes, informes constatando a presença do ex-capitão CARLOS LAMARCA no RGS. Fontes: Diversas. Local: Canoas, Camaquã, Hidrelétrica, etc. Classificação: INFES. Providência de Correlação: Em todas as oportunidades foram tomadas providências de ampliar o informe e localização, inclusive com estabelecimentos de barreiras e deslocamento de pessoal as áreas. ${ }^{30}$

A presença de Carlos Lamarca seria constante no espaço estadual, porque Porto Alegre formaria, junto com as cidades de Curitiba, Rio de Janeiro, e São Paulo, o eixo de operações da VPR em âmbito nacional. A relação do ex-capitão com a esquerda do Rio Grande do Sul, no entanto, teria iniciado em 1966, período no qual ele serviu na capital e manteve contato com um oficial da Força Aérea Brasileira (FAB), conhecido por "Daut", supostamente detido por envolvimento em atividades políticas subversivas. A repressão desferida contra Lamarca foi tão intensa que ele se tornou

\footnotetext{
${ }^{28}$ Arquivo Histórico do Rio Grande do Sul /Fundo: Secretaria da Segurança Pública/ Subfundo: Polícia Civil/Departamento de Polícia do Interior/ $20^{\mathrm{a}}$ Região Policial/ Delegacia Regional de Cachoeira do Sul/ SOPS/ SOPS/CS 1.-.57.1.1, "Síntese de Ocorrências Suspeitas", Porto Alegre, 17 de fevereiro de 1970.

${ }^{29}$ Arquivo Histórico do Rio Grande do Sul /Fundo: Secretaria da Segurança Pública/ Subfundo: Polícia Civil/Departamento de Polícia do Interior/ $15^{\mathrm{a}}$ Região Policial/ Delegacia Regional de Lagoa Vermelha/ SOPS/ SOPS/LV 1.-.70.1.1, "Responde às solicitações contidas no informe n 396/69 do D.C.I", Vacaria, 03 de janeiro de 1970.

${ }^{30}$ Arquivo Histórico do Rio Grande do Sul /Fundo: Secretaria da Segurança Pública/ Subfundo: Polícia Civil/Departamento de Polícia do Interior/ 20ª Região Policial/ Delegacia Regional de Cachoeira do Sul/ SOPS/ SOPS/CS 1.-.57.1.1, "Diário de informações”, Porto Alegre, 30 de janeiro de 1970.
} 
uma das pessoas mais procuradas do país. A explicação para o fato está nas próprias Forças Armadas, que baseando suas prerrogativas na hierarquia e na disciplina não aceitavam o fato de ele ter abandonado o Exército para integrar uma organização de esquerda que havia optado pela luta arma$\mathrm{da}$, sintetizadas na seguinte frase: "Poderia ser comunista aquele que era considerado "bom oficial" do $4^{\circ}$ Regimento de Infantaria?”. Lamarca era considerado um traidor, um inimigo, não apenas dos militares, como da própria "nação brasileira". ${ }^{31}$

Padrós enfatizou que no período em que vigoraram ditaduras de SN no Cone Sul, as Forças Armadas de seus países compartilhavam determinados compromissos, entre os quais estava a necessidade de manutenção da disciplina e da obediência à hierarquia institucional. Na medida em que transcorriam os governos militares, esses compromissos serviram tanto para "diluir" entre a corporação as responsabilidades pelos atos arbitrários praticados no período, ao mesmo tempo em que diminuíram a ocorrência de "perigosas deserções". Os militares que não aderiram ou se posicionaram contra os regimes de exceção, tornaram-se alvos do aparato repressivo e do mesmo tipo de violência empregada por eles contra os "subversivos", que culminou, em alguns casos com a chamada "queima de arquivo". Em todos os casos, "a quebra do compromisso corporativo condena os desertores à condição de traidores, antipatriotas; pior, traidores entre camaradas de armas, fato imperdoável." 32

A necessidade de acabar com as atividades da VPR e das demais organizações fizeram com que os órgãos de segurança aplicassem métodos terroristas de forma sistemática contra os militantes da luta armada no Rio Grande do Sul. João Carlos Bona Garcia, por exemplo, foi perseguido, preso e encaminhado aos DOPS/RS, local onde foi submetido a torturas físicas, entre as quais sessões de espancamentos e choques elétricos e torturas

\footnotetext{
${ }^{31}$ Arquivo Histórico do Rio Grande do Sul /Fundo: Secretaria da Segurança Pública/ Subfundo: Polícia Civil/Departamento de Polícia do Interior/ 20a Região Policial/ Delegacia Regional de Cachoeira do Sul/ SOPS/ SOPS/CS 1.2.1408.18.5, "Carlos Lamarca, Ex-Capitão do Exército", Porto Alegre, 27 de abril de 1970.
}

${ }^{32}$ PADRÓS, Enrique Serra. Op. cit., p.96. 
psicológicas, como amedrontamento, ameaças desferidas contra ele e sua família e tentativas de quebrar a sua moral como militante. Ele resistiu a tortura e não forneceu nenhum tipo de informação sobre a VPR e seus companheiros aos torturadores, pois tinha consciência da situação na qual se encontrava na delegacia, ou seja, avaliou que os agentes o manteriam vivo enquanto não falasse, caso contrário se tornaria uma "vítima dispensável" e poderia, a qualquer momento, ser assassinado. O delegado Pedro Seelig e seus assessores: Nilo Hervelha e o major Átila Rohrsetzer, tentavam desestruturar os militantes da seguinte forma:

Ora fazendo namorados se torturarem reciprocamente; ora torturando todo um dia, dando depois calmantes para a pessoa dormir, mas não deixando dormir. Em tensão constante, a pessoa começa a perder a noção do dia, da noite, começa a perder a consciência, que é o que mais mantém sua estrutura. Tentavam tirar o equilíbrio que a pessoa tem. Muitos, quando voltavam para a cela depois da tortura, naquele estado lastimável caíam em sono, começavam a sonhar e no sonho faziam as revelações que o torturador não arrancava deles quando em estado de consciência (...). A tortura que faziam procurava aniquilar física e moralmente. ${ }^{33}$

De acordo com Bauer, a sistematização da tortura no DOPS/RS ocorria da seguinte forma: o preso que chegava à delegacia era submetido a dois processos sequenciais, o "chá de banco" e o "amaciamento". A ideia do primeiro era criar no indivíduo um clima de expectativa em relação ao interrogatório, porque era algo que o submetido não podia prever, enquanto o segundo tinha por finalidade abalar a sua estrutura emocional, quebrando a resistência do militante frente aos torturadores. Na próxima etapa, o preso político passava pelo verdadeiro "interrogatório", ou seja, nessa fase, era submetido a sessões de torturas físicas e psicológicas empreendidas por agentes "especializados" na aplicação dos métodos de suplício. De acordo com pesquisa divulgada pelo projeto Brasil: Nunca Mais, das "122 denúncias de torturas praticadas no estado, 43\% dos casos ocorreram nas dependências do DOPS/RS". A militarização do órgão teria começado com o golpe civil-militar de 1964 e se

${ }^{33}$ GARCIA, João Carlos Bona; POSENATO, Julio. Op. cit., p.54. 
tornado mais eficiente na medida em que a repressão se institucionalizava, não apenas no estado, como em todo o país. ${ }^{34}$

Jorge Fischer descreveu os suplícios que sofreu nas dependências do DOPS/RS em seu livro de memórias "O riso dos torturados". Ele relatou que após ter sido preso e ameaçado pelos policiais da delegacia, ele foi colocado no pau-de-arara e de cabeça para baixo sofreu sessões de espancamento, choques e afogamento, por um período descrito como o "mais longo de toda a sua vida"; a tortura deformou uma de suas pernas e comprometeu a circulação sanguínea, que acabaram impossibilitando o ex-militante de trabalhar normalmente. Ele descreveu o DOPS como um "inferno compartimentado", "burocratizado" por agentes que denominou como "infernais funcionários da dor":

Ali, no saguão os homens ficavam aguardando a sua vez de partir para
a tortura, como bois no matadouro, ouvindo os gemidos dos compa-
nheiros que iam sendo massacrados. No salão mais em cima ficava a
"coréia". Para lá eram remetidos os que haviam passado pelo pior. Dois
brigadianos carregavam o molambo e jogavam-no na "coréia" como es-
tivadores que jogam um saco de batatas. E ali a gente ficava cozinhando
a dor, ruminando o medo, aguardando a próxima vez de ser torturado. ${ }^{35}$

Índio Vargas também passou por sessões de tortura no DOPS/RS, principalmente com choques elétricos, mas a tarefa mais difícil para ele, o que "arrebentou os seus nervos", foi assistir à tortura de dois de seus companheiros $^{36}$. Para o psicanalista Hélio Pellegrino, a aplicação da tortura tem por objetivo provocar uma "cisão entre o corpo e a mente" do indivíduo, através da aplicação de uma dor insuportável. Assim, a atividade de todo o torturador se baseia na certeza de que em um determinado momento a

\footnotetext{
${ }^{34}$ BAUER, Carolina Silveira. Avenida João Pessoa, 2050- $3^{\circ}$ andar: Terrorismo de Estado e ação de polícia política do Departamento de Ordem Política e Social do Rio Grande do Sul (1964-1982). Porto Alegre: UFRGS, 2006. Dissertação (Mestrado História) - Programa de Pós-Graduação em História, Instituto de Filosofia e Ciências Humanas, Universidade Federal do Rio Grande do Sul, Porto Alegre, 2006, p.84.

${ }^{35}$ FISCHER, Jorge. O riso dos torturados. Porto Alegre: Poletra, 1982, p. 62.

${ }^{36}$ VARGAS, Índio. Guerra é guerra, dizia o torturador. Rio de Janeiro: Codecri, 1981, p. 65. 
pessoa não vai suportar a dor física a que está sendo submetida e o próprio corpo vai se voltar contra ela, exigindo que fale. A tortura nega a própria liberdade da pessoa, "enquanto ser encarnado":

O centro da pessoa humana é a liberdade. Esta, por sua vez, é a invenção que o sujeito faz de si mesmo, através da palavra que o exprime. Na tortura, o discurso que o torturador busca extrair o torturado e a negação absoluta e radical de sua condição de sujeito livre. A tortura visa ao avesso da liberdade. Nesta medida, o discurso que ela busca, através da intimidação e da violência, é a palavra aviltada de um sujeito que, nas mãos do torturador, se transforma em objeto. ${ }^{37}$

Marcelo Viñar, psicanalista vítima de tortura no período em que vigorou uma ditadura de SN no Uruguai, escreveu que a sua aplicação se baseia em três fases sucessivas; a primeira consiste em aniquilar o indivíduo, destruindo os seus valores e as suas convicções, a segunda se baseia na desorganização do sujeito e da relação que ele mantinha com o mundo, que o médico chamou de "demolição" e a terceira seria aquele momento no qual a pessoa atinge sua "situação limite" e decide qual a atitude vai tomar a seguir, pois ela é atingida quando o corpo submetido ao sofrimento intenso provoca no sujeito uma "experiência destruidora, de abandono". A posição que a pessoa adota após essa experiência varia de acordo com sua personalidade, vivência e estrutura psíquica, bem como o tempo no qual ela é atingida, que pode variar de um período de horas, dias ou meses de submissão ao sofrimento. A tortura provoca no indivíduo: "uma ruptura de todo laço afetivo e efetivo com o mundo pessoal amado desde sempre, conduzem a solitária presença constante de um corpo dolorido, sofrido, desfeito, totalmente à mercê do torturador". ${ }^{38}$

A aplicação de tortura sistemática sobre os presos políticos no DOPS/ RS resultou no desmantelamento das principais organizações de luta armada, que o jornal Zero Hora descreveu, três dias após a tentativa de sequestro do cônsul em Porto Alegre, como sendo a VPR, a VAR-P e o M-G3, segui-

\footnotetext{
${ }^{37}$ ARNS, Paulo Evaristo. Op. cit., p. 02.

${ }^{38}$ VIÑAR, Maren e Marcelo. Exílio e tortura. São Paulo: Escuta, 1992, p.111. 
das pelo POC (Partido Operário Comunista) e a União Operária ${ }^{39}$.Logo, a Folha de São Paulo noticiou a prisão de Edmur Péricles de Camargo, do M-G3, e a desarticulação de uma importante célula do movimento subversivo no estado. A polícia também informava que através do "interrogatório" de alguns militantes presos eles haviam chegado até Gustavo Buarque Schiller, pessoa encarregada de trazer do Rio de Janeiro a lista contendo os nomes de doze presos políticos que deveriam ser libertados em troca do cônsul, caso o sequestro tivesse alcançado êxito. ${ }^{40}$

No mês seguinte, os órgãos de segurança divulgaram a descoberta de uma área de treinamento da VPR na região do Alto Uruguai e o envio de uma equipe formada por agentes do Centro de Informações do Exército (CIE), da Secretaria de Segurança Pública e militares do III Exército para interrogar os militantes presos durante a operação. Logo, os agentes divulgaram algumas informações obtidas através dos interrogatórios desses militantes; o médico do grupo, por exemplo, declarou manter contato com os militantes Felix Silveira Rosa Neto, o "Frank", do Setor de Inteligência, "Lya", do Comando Nacional e Roberto de Fortini, os quais lhe instruíram para convencer outros profissionais a integrarem a base médica da VPR na área, mas que até aquele momento ele não teria conseguido executar a tarefa. Além da equipe especializada em interrogatório, um grupo de Fuzileiros Navais foi encaminhado para vasculhar a região em busca de outras bases da VPR. ${ }^{41}$

As informações sobre Carlos Lamarca obtidas durante os interrogatórios permitiram que os órgãos de segurança soubessem que o ex-capitão havia sido submetido a uma cirurgia plástica e providenciado documentos falsificados para tentar fugir do Brasil utilizando a região de fronteira do Rio Grande do Sul:

\footnotetext{
${ }^{39}$ Zero Hora, "Cônsul seria trocado por doze presos políticos de São Paulo", 08 de abril de 1970, p. 28. Arquivo Público de São Paulo.

${ }^{40}$ Folha de São Paulo, "Polícia gaúcha desmonta célula", 10 de abril de 1970, s.p. Arquivo Público de São Paulo.

${ }^{41}$ Arquivo Histórico do Rio Grande do Sul/Fundo: Secretaria da Segurança Pública/ Subfundo: Polícia Civil/Departamento de Polícia do Interior/ 20a Região Policial/ Delegacia Regional de Cachoeira do Sul/ SOPS/ SOPS/CS 3.-.4402.53.15, "Apreensão de armas", Porto Alegre, 06 de maio de 1970.
} 
DOPS urgente reservado 198 pt: Carlos Lamarca vg atualmente usando identidade Luigi Santini vg cabelos alourados vg com possíveis leves cicatrizes rosto junto nariz vg talvez com óculos escuros vg poderá tentar sair de o nosso estado próximas horas motivo ter sido constatada presença mesmo em palegre pt em consequencia determino desencadear severa fiscalizaçâo e montagem barreiras bem como controle população flutuante pt dar ciencia presente radio comando unidades exercito e brigada pedindo apoio indispensavel pt lembro abordagem carros vg onibus e caminhoes maximo cuidado. ${ }^{42}$

Carlos Lamarca não fugiu para o exterior como indicava o informe e um ano mais tarde deixou a VPR para ingressar no Movimento Revolucionário 8 de outubro (MR-8), que na época havia comprovado a redução de suas bases sociais e a dificuldade em atrair novos indivíduos para recompor o quadro de militantes atingidos pela repressão. Por essa razão, o MR-8 decidiu abandonar a luta armada no meio urbano para retomar o trabalho de massas e preparar a guerrilha rural. Em junho, o ex-capitão viaja para a Bahia com a finalidade de recrutar camponeses para fundar uma área estratégica da guerrilha rural, prevista para ser implantada na região de fronteira entre o estado e Goiás. No entanto, a repressão alcança alguns militantes da organização, que são presos e durante interrogatório fornecem informações sobre a tentativa de implantação da guerrilha. Em seguida, Carlos Lamarca e Zequinha são localizados e executados no município de Pintada, pela tropa do major Nilton de Albuquerque Cerqueira, chefe do DOI/CODI de Salvador. ${ }^{43}$

Em relação ao Rio Grande do Sul, os órgãos de segurança apresentaram, em junho de 1970, uma avaliação geral sobre o desmantelamento da esquerda armada no estado, indicando os militantes que haviam sido libertados depois de prestarem depoimento, aqueles que foram encaminhados para prisões em São Paulo ou na Guanabara, além dos nomes dos detidos pela segunda vez e também dos foragidos. Em relação a VPR, os militantes foragidos eram os

\footnotetext{
${ }^{42}$ Arquivo Histórico do Rio Grande do Sul /Fundo: Secretaria da Segurança Pública/ Subfundo: Polícia Civil/Departamento de Polícia do Interior/ 20ª Região Policial/ Delegacia Regional de Cachoeira do Sul/ SOPS/ SOPS/CS 1.2.1410.18.5, "Radiograma: Carlos Lamarca", Porto Alegre, 21 de maio de 1970.
}

${ }^{43}$ GORENDER, Jacob. Op. cit., p. 225. 
seguintes: Leane Ferreira da Almeida, companheira de Irgeu João Menegon (militante transferido para a Guanabara); Sérgio Azambuja Círio, arquiteto que fez treinamento de guerrilha em Cuba e Valmeri Neves Antunes, que atuava na área tática de Registro, São Paulo. Já o militante Almir Duton Ferreira se encontrava preso numa delegacia da Guanabara e Carlos Pinto da Silva, acusado de comprar armas para a VPR, foi libertado pela polícia. ${ }^{44}$

Outros militantes da VPR foram libertados em janeiro de 1971, ao serem trocados pelo embaixador suíço Giovanni Enrico Bucher, sequestrado no ano anterior pela VPR. O governo militar organizou uma campanha na imprensa de difamação dos setenta presos libertados e posteriormente, banidos do território nacional. O Globo, por exemplo, na matéria intitulada "Os crimes dos 70 subversivos banidos" informava o seguinte: João Carlos Bona Garcia esteve envolvido em vários atos de subversão e terrorismo no Rio Grande do Sul; Gustavo Buarque Schiller participou do roubo ao cofre da casa de Ana Bechimol Capriglioni, que rendeu 2,4 milhões de dólares para a VPR e a VAR-P, assaltos a bancos e compras de armas no exterior, além da tentativa de sequestro do cônsul em Porto Alegre; Roberto Antonio de Fortini era acusado de comandar a área tática da VPR na cidade de Três Passos e Bruno Piola, de abastecer o local com armas e munições. ${ }^{45}$

Os setenta presos políticos foram banidos do Brasil através de uma lei criada pelo governo militar, após o sequestro do embaixador americano Charles Burke Elbrick, realizado em setembro de 1969, que resultou no banimento de quinze presos políticos para o México. Os órgãos de segurança alertavam que se algum dos quinze militantes resolvesse voltar ao território nacional, o fato deveria ser imediatamente comunicado a uma autoridade federal. ${ }^{46}$

\footnotetext{
${ }^{44}$ Arquivo Histórico do Rio Grande do Sul /Fundo: Secretaria da Segurança Pública/ Subfundo: Polícia Civil/Departamento de Polícia do Interior/ 20a Região Policial/ Delegacia Regional de Cachoeira do Sul/ SOPS/ SOPS/CS 1.2.1417.18.5, "Subversão no RGS", Porto Alegre, 18 de junho de 1970.

${ }^{45}$ O Globo, "Os crimes dos 70 subversivos banidos”, 12 de janeiro de 1971, s/p. Arquivo Público de São Paulo.

${ }^{46}$ Arquivo Histórico do Rio Grande do Sul /Fundo: Secretaria da Segurança Pública/ Subfundo: Polícia Civil/Departamento de Polícia do Interior/ 20a Região Policial/ Delegacia 
O governo militar instituiu a lei de banimento através do Ato Institucional $\mathrm{n}^{\mathrm{o}} 13$, datado de 5 de setembro de 1969, que declarava em seu artigo primeiro o seguinte:"O Poder Executivo poderá, mediante proposta dos Ministros de Estado da Justiça, da Marinha de Guerra, do Exército ou da Aeronáutica Militar, banir do Território Nacional o brasileiro que, comprovadamente, se tornar inconveniente, nocivo ou perigoso à Segurança Nacional." ${ }^{.47}$

O sequestro do embaixador suíço foi o último realizado por organizações de luta armada no país, pois as negociações entre a VPR e o governo militar foram bastante complicadas e duraram mais de um mês, pois os militares rejeitaram vários nomes presentes na lista enviada pela organização, como o das pessoas envolvidas nos chamados crimes de sangue. O país para os quais os militantes banidos deveriam ser enviados também gerava controvérsias, pois havia a possibilidade deles seguirem para o Chile, o México ou a Argélia. O Chile acabou sendo o destino escolhido, uma vez que o país tinha a frente do poder executivo o socialista Salvador Allende, que se comprometeu a receber e manter todos os exilados enquanto eles respeitassem as leis chilenas e as condições estabelecidas para o seu acolhimento. ${ }^{48}$

\section{Considerações finais}

Os métodos terroristas empregados contra a VPR e outras organizações de esquerda no Rio Grande do Sul, além de aniquilar a luta armada, propagou o terror na sociedade, pois não atingiu apenas o indivíduo qualificado como "subversivo" e "inimigo interno", mas também familiares, amigos e pessoas de seu entorno social. O medo impediu que as pessoas

Regional de Cachoeira do Sul/ SOPS/ SOPS/CS 1.-.34.1.1, "Presos políticos banidos para o México pelo Governo Brasileiro”, Porto Alegre, 7 de outubro de 1969.

${ }^{47}$ Arquivo Histórico do Rio Grande do Sul /Fundo: Secretaria da Segurança Pública/ Subfundo: Polícia Civil/Departamento de Polícia do Interior/ $15^{\mathrm{a}}$ Região Policial/ Delegacia Regional de Lagoa Vermelha/ SOPS/ SOPS/LV 4.-.5775.52.18, "Ato Institucional n 13", 05 de setembro de 1969.

${ }^{48}$ O Globo, “O governo decide: vão seguir para o Chile todos os 70 banidos”, 12 de janeiro de 1971, p. 5. Arquivo Público de São Paulo. 
continuassem a aderir aos grupos de esquerda, porque a militância política conduzia quase inevitavelmente a perseguição, prisão e a tortura. A apatia política passou a ser a melhor forma do indivíduo não se tornar uma vítima do TDE, já que a repressão não ficava restrita aos opositores armados e não armados do regime, mas se estendia a pessoas sem histórico de envolvimento em atividades políticas. A aplicação do TDE provocou o surgimento do que Padrós chamou de "cultura do medo", ainda fortemente arraigada a sociedade brasileira e dos demais países do Cone Sul onde também vigoraram Ditaduras de SN, que resultou na manutenção de resquícios autoritários e no imobilismo político da população.

Nesse contexto, os 50 anos do golpe-civil militar de 1964 trazem para o debate social questões pertinentes sobre a violação dos direitos humanos que ocorreram no Brasil durante a ditadura de SN e da lei da anistia, promulgada em 1978, que até o momento impediu que os torturadores e também as pessoas responsáveis por estruturar e coordenar o aparato repressivo fossem julgados pelos crimes cometidos a serviço do Estado. Os setores vinculados ao regime de exceção defendem que a melhor política é a do esquecimento, pois ela permitiria ao país a possibilidade de "seguir em frente", como se um passado de tal forma traumático pudesse, a qualquer momento, ser “deixado para trás”. Por outro lado, as vítimas, seus familiares, órgãos de defesa dos Direitos Humanos, pesquisadores e outros setores da sociedade se engajaram na luta pela verdade, que visa o esclarecimento, entre outras coisas, de questões vinculadas aos desaparecimentos de presos políticos e a identificação e punição dos responsáveis pelo emprego da tortura e dos demais métodos terroristas no período. Em época de Comissão da Verdade, qualquer conclusão que não atenda as reivindicações das vítimas e de seus familiares, ao invés de promover a conciliação nacional, vai apenas perpetuar a política da injustiça e da impunidade no Brasil. 